\title{
Recent patents in cancer vaccines
}

\begin{tabular}{|c|c|c|c|c|c|}
\hline Patent \# & Subject & Assignee & Author & Date & Status \\
\hline WO 9918210 & $\begin{array}{l}\text { Isolated polypeptides and DNA obtained from prostate } \\
\text { tumor cells for the treatment, diagnosis, and monitoring } \\
\text { of prostate cancer. }\end{array}$ & $\begin{array}{l}\text { Corixa } \\
\text { (Seattle, WA) }\end{array}$ & $\begin{array}{l}\text { Dillon DC, } \\
\text { Mitcham JL, } \\
\text { Reed SG, } \\
\text { Twardzik DR }\end{array}$ & $4 / 15 / 99$ & A2 \\
\hline EP 908521 & $\begin{array}{l}\text { A new transfection system comprising a histone protein; } \\
\text { useful in vaccine and gene therapy compositions and drug } \\
\text { screening assays for cancer, HIV, Alzheimer's disease, } \\
\text { and diabetes. }\end{array}$ & $\begin{array}{l}\text { Hoechst Marion } \\
\text { Roussel (Frank- } \\
\text { furt, Germany) }\end{array}$ & $\begin{array}{l}\text { Chandra A, } \\
\text { Chandra P, } \\
\text { Dermirhani I, } \\
\text { Hasselmayer O }\end{array}$ & 4/14/99 & $\mathrm{A} 1$ \\
\hline WO 9916466 & $\begin{array}{l}\text { Vaccine compositions comprising a vaccine and a } \\
\text { timed-release formulation of a cytokine or cytokine/ } \\
\text { immunoglobulin fusion protein or plasmid. }\end{array}$ & $\begin{array}{l}\text { Beth Israel } \\
\text { Deaconess Med. } \\
\text { Center } \\
\text { (Boston, MA) }\end{array}$ & $\begin{array}{l}\text { Barouch DH, } \\
\text { Letvin NL }\end{array}$ & $4 / 8 / 99$ & $\mathrm{~A} 2$ \\
\hline WO 9915627 & $\begin{array}{l}\text { Cellular immunopotentiating composition containing } \\
\alpha \text {-glycosylceramide for use in the prevention and treatment } \\
\text { of cancer and infectious diseases, e.g., by incorporation of } \\
\text { immunogenicity potentiated tumor cells into a vaccine. }\end{array}$ & $\begin{array}{l}\text { Kirin Beer KK } \\
\text { (Tokyo) }\end{array}$ & Motoli K & $4 / 1 / 99$ & $\mathrm{~A} 1$ \\
\hline WO 9915201 & $\begin{array}{l}\text { A composition comprising a fucosyl GM1 ganglioside or its } \\
\text { oligosaccharide portion conjugated to an immunogenic pro- } \\
\text { tein for enhancing or stimulating antibody production, to be } \\
\text { used as a vaccine against small cell lung cancer. }\end{array}$ & $\begin{array}{l}\text { Sloan Kettering } \\
\text { Inst. Cancer } \\
\text { Research } \\
\text { (New York) }\end{array}$ & $\begin{array}{l}\text { Livingston PO, } \\
\text { Ragupathi G }\end{array}$ & $4 / 1 / 99$ & $\mathrm{~A} 1$ \\
\hline WO 9915199 & $\begin{array}{l}\text { A vaccine comprising modified mesenchymal stem cells/ } \\
\text { adipocytes so that an exogenous antigen binds to a primary } \\
\text { surface molecule, allowing cells to express costimulatory } \\
\text { molecules and inducing an in vivo antigen-specific } \\
\text { T-cell response. }\end{array}$ & $\begin{array}{l}\text { Osiris Therapeutics } \\
\text { (Baltimore, MD) }\end{array}$ & Mosca JD & $4 / 1 / 99$ & $\mathrm{~A} 1$ \\
\hline US 5888516 & $\begin{array}{l}\text { A human papillomavirus vaccine, useful for preventing } \\
\text { benign warts, nonmalignant condrylomata, cancer, } \\
\text { genital warts, and laryngeal papillomas. }\end{array}$ & $\begin{array}{l}\text { Merck \& Co. } \\
\text { (Whitehouse } \\
\text { Station, NJ) }\end{array}$ & $\begin{array}{l}\text { Cook JC, George HA, } \\
\text { Jansen KU, Joyce } \\
\text { JG, Lehman ED, } \\
\text { Markus HZ, } \\
\text { Rosolowsky M, } \\
\text { Schultz LS }\end{array}$ & 3/30/99 & $A$ \\
\hline WO 9914230 & $\begin{array}{l}\text { An isolated and purified polypeptide containing mammaglobin, } \\
\text { a secreted protein overexpressed in breast cancer, for use } \\
\text { in vaccines. }\end{array}$ & $\begin{array}{l}\text { Univ. Washington } \\
\text { (Seattle, WA) }\end{array}$ & $\begin{array}{l}\text { Fleming TP, } \\
\text { Watson MA }\end{array}$ & $3 / 25 / 99$ & $A$ \\
\hline WO 9911284 & $\begin{array}{l}\text { A vaccine containing lactobacilli expressing urease peptide } \\
\text { for treating stomach cancer, chronic dyspepsia, refractory } \\
\text { ulcer dyspepsia, and other gastrointestinal disorders. }\end{array}$ & $\begin{array}{l}\text { Queen Mary \& } \\
\text { Westfield College } \\
\text { (London) }\end{array}$ & $\begin{array}{l}\text { Tabaqchali S, } \\
\text { Wilks M }\end{array}$ & 3/11/99 & $\mathrm{A} 1$ \\
\hline WO 9909139 & $\begin{array}{l}\text { Retroviral sequences that have a novel replication strategy, } \\
\text { allowing extrachromosomal replication of DNA; useful in } \\
\text { vaccines and gene therapy techniques, especially when the } \\
\text { polynucleotide construct or vaccine comprises a foreign gene. }\end{array}$ & Rubicon Lab Inc. & Lauermann V & 2/25/99 & $\mathrm{A} 1$ \\
\hline WO 9907869 & $\begin{array}{l}\text { A live recombinant vaccine comprising a heterologous } \\
\text { polynucleotide molecule encoding antigen; useful for } \\
\text { inducing a protective immune response, cancer } \\
\text { prevention, and fertility control. }\end{array}$ & $\begin{array}{l}\text { Univ. Florida } \\
\text { (Gainesville, FL); } \\
\text { US Dept. Health } \\
\text { \& Human Services }\end{array}$ & $\begin{array}{l}\text { Bender BS, } \\
\text { Meitin CA, } \\
\text { Moss B, Small PA }\end{array}$ & 2/19/99 & $\mathrm{A} 1$ \\
\hline EP 894863 & $\begin{array}{l}\text { New serine-threonine kinase (HTLAR33) polypeptides and } \\
\text { polynucleotides; useful as diagnostic reagents and for preven- } \\
\text { tion and treatment of bone loss, neurological and inflammatory } \\
\text { disorders, cancer, HIV infections, and angina pectoris. }\end{array}$ & $\begin{array}{l}\text { SmithKline Beecham } \\
\text { (Philadelphia, PA) }\end{array}$ & $\begin{array}{l}\text { Bergsma DJ, } \\
\text { Shabon U }\end{array}$ & $2 / 3 / 99$ & A1 \\
\hline EP 894855 & $\begin{array}{l}\text { New human I kappa B- } \beta \text { transcription factor polypeptide } \\
\text { and polynucleotide; useful as diagnostic reagents and for } \\
\text { prevention and treatment of AIDS, cancer, and arthritis. }\end{array}$ & $\begin{array}{l}\text { SmithKline Beecham } \\
\text { (Philadelphia, PA) }\end{array}$ & Chabot-Fletcher MC & $2 / 3 / 99$ & A2 \\
\hline
\end{tabular}

